University of Nebraska - Lincoln

DigitalCommons@University of Nebraska - Lincoln

USGS Staff -- Published Research

US Geological Survey

2009

Acute oral toxicities of wildland fire control chemicals to birds

Nimish B. Vyas

USGS Patuxent Wildlife Research Center, nvyas@usgs.gov

James W. Spann

USGS Patuxent Wildlife Research Center

Elwood F. Hill

USGS Patuxent Wildlife Research Center

Follow this and additional works at: https://digitalcommons.unl.edu/usgsstaffpub

Vyas, Nimish B.; Spann, James W.; and Hill, Elwood F., "Acute oral toxicities of wildland fire control chemicals to birds" (2009). USGS Staff -- Published Research. 579.

https://digitalcommons.unl.edu/usgsstaffpub/579

This Article is brought to you for free and open access by the US Geological Survey at DigitalCommons@University of Nebraska - Lincoln. It has been accepted for inclusion in USGS Staff -- Published Research by an authorized administrator of DigitalCommons@University of Nebraska - Lincoln. 


\title{
Acute oral toxicities of wildland fire control chemicals to birds
}

\author{
Nimish B. Vyas*, James W. Spann, Elwood F. Hill \\ USGS Patuxent Wildlife Research Center, Beltsville Lab, c/o BARC-East Bldg 308, 10300 Baltimore Avenue, Beltsville, MD 20705, USA
}

\section{A R T I C L E I N F O}

\section{Article history:}

Received 13 March 2008

Received in revised form

2 September 2008

Accepted 7 September 2008

Available online 26 November 2008

\section{Keywords:}

American kestrel

Fire-Trol GTS-R ${ }^{\mathrm{TM}}$

Fire-Trol LCG-R ${ }^{\mathrm{TM}}$

Foams

Northern bobwhite

Phos-Chek D-75F ${ }^{\mathrm{TM}}$

Phos-Chek WD881 ${ }^{\mathrm{TM}}$

Red-winged blackbird

Retardants

Silv-Ex ${ }^{\mathrm{TM}}$

\begin{abstract}
A B S T R A C T
Wildland fire control chemicals are released into the environment by aerial and ground applications to manage rangeland, grassland, and forest fires. Acute oral $24 \mathrm{~h}$ median lethal dosages (LD50) for three fire retardants (Fire-Trol GTS- $\mathrm{R}^{\mathrm{TM}}$, Phos-Chek $\mathrm{D}-75 \mathrm{~F}^{\mathrm{TM}}$, and Fire-Trol LCG-R ${ }^{\mathrm{TM}}$ ) and two Class A fire suppressant foams (Silv-Ex ${ }^{\mathrm{TM}}$ and Phos-Chek WD881 ${ }^{\mathrm{TM}}$ ) were estimated for northern bobwhites, Colinus virginianus, American kestrels, Falco sparverius, and red-winged blackbirds, Agelaius phoeniceus. The LD50s of all chemicals for the bobwhites and red-winged blackbirds and for kestrels dosed with Phos-Chek WD881 ${ }^{\mathrm{TM}}$ and Silv-Ex ${ }^{\mathrm{TM}}$ were above the predetermined $2000 \mathrm{mg}$ chemical $/ \mathrm{kg}$ body mass regulatory limit criteria for acute oral toxicity. The LD50s were not quantifiable for kestrels dosed with Fire-Trol GTS- $\mathrm{R}^{\mathrm{TM}}$, Phos-Chek D-75F $\mathrm{F}^{\mathrm{TM}}$, and Fire-Trol LCG- $\mathrm{R}^{\mathrm{TM}}$ because of the number of birds which regurgitated the dosage. These chemicals appear to be of comparatively low order of acute oral toxicity to the avian species tested.
\end{abstract}

(c) 2008 Published by Elsevier Inc.

\section{Introduction}

Wildland fire control chemicals are mixed with water and applied to forests, rangelands, and grasslands to manage wildfires. These compounds, retardants and suppressant foams, are classified by their mode of action and duration of activity. Retardants form a combustion inhibiting agent on the fuel source thereby decreasing fire intensity and slowing its advance. These compounds are applied ahead of the fire to create barrier zones for containing the fire's spread. Retardants are long-term protectants since they are effective even after the water they originally were applied with has evaporated (George et al., 1976). Suppressant foams are used directly on the fire, to create firebreaks, and during mop-up. Foams inhibit combustion by increasing water retention on fuel sources but they provide short-term protection because they lose their effectiveness as the water that they were applied with evaporates (McKenzie, 1992).

Retardants and suppressant foams are released into the environment by aerial and ground applications. Birds are exposed to the un-combusted wildland fire control chemicals while foraging in areas that are sprayed with the compounds but are peripheral to the fire. Human effects literature suggests low mammalian acute oral toxicities for the wildland fire control formulations that were selected for this study (USDA Forest

\footnotetext{
* Corresponding author. Fax: +1310 4975744.

E-mail addresses: nvyas@usgs.gov, nbvyas@comcast.net (N.B. Vyas).
}

Service http://www.fs.fed.us/rm/fire/wfcs/msds.htm\#ltretard, accessed 10 December 2007); however information is lacking on the acute oral toxicities of these chemicals to avian species. We conducted acute oral toxicity testing using five commonly used wildland fire control chemicals on three species of birds.

\section{Materials and methods}

This study was approved by the US Geological Survey Patuxent Wildlife Research Center's Animal Care and Use Committee.

References to trade names, manufacturers, or commercial products do not imply endorsement by the Biological Resources Division, US Geological Survey, Department of the Interior. The acute oral toxicities of three retardants (Fire-Tro GTS-R ${ }^{\mathrm{TM}}$, Phos-Chek D-75F ${ }^{\mathrm{TM}}$, and Fire-Trol LCG- $\mathrm{R}^{\mathrm{TM}}$ ) and two Class A suppressant foams (Silv-Ex ${ }^{\mathrm{TM}}$ and Phos-Chek WD881 $1^{\mathrm{TM}}$ ) were determined using northern bobwhites, Colinus virginianus, American kestrels, Falco sparverius, and red-winged blackbirds, Agelaius phoeniceus. Fire-Trol GTS-R ${ }^{\mathrm{TM}}$ consists of ammonium sulfate, diammonium phosphate, guar gum thickener, spoilage inhibitor, corrosion inhibitors, and iron oxide as a colorant (USDA Forest Service http://www.fs. fed.us/rm/fire/wfcs/products/msds/retard/firetrol/ft_gts-r.pdf, accessed 12 December 2007). Phos-Chek D-75F ${ }^{\mathrm{TM}}$ contains diammonium sulfate, monoammonium phosphate, diammonium phosphate, guar gum thickener, viscosity stabilizers, corrosion inhibitor, and fugitive agent (USDA Forest Service http://www.fs.fed.us/ rm/fire/wfcs/products/pc_d75rf.htm, accessed 12 December 2007; ICL Performance Products http://www.phoschek.com/shared/content_objects/product objects//AST10035_1600_EN_PhosChek_D75F_D75R.pdf, accessed 12 December 2007). Fire-Trol LCG- $\mathrm{R}^{\mathrm{TM}}$ is composed of ammonium polyphosphate, attapulgite clay thickener, corrosion inhibitor, and iron oxide as a coloring agent (USDA Forest Service http://www.fs.fed.us/rm/fire/wfcs/products/ft_lcg-r.htm, accessed 12 December 2007). Silv-Ex ${ }^{\mathrm{TM}}$ is a mixture of diethylene glycol monobutyl ether, ethyl alcohol, sodium and ammonium salts of fatty alcohol ether sulfates $\left(C_{8}-C_{18}\right)$, 
higher alcohols, and water (USDA Forest Service http://www.fs.fed.us/rm/fire wfcs/products/msds/foam/silvex.pdf, accessed 12 December 2007). Phos-Chek WD881 ${ }^{\mathrm{TM}}$ is comprised of anionic surfactants, alcohol, hexylene glycol, and water (USDA Forest Service http://www.fs.fed.us/rm/fire/wfcs/products/msds/foam/ wd881c.pdf, accessed 12 December 2007). The Material Safety Data Sheets provide no persistence and degradation studies for Fire-Trol GTS- ${ }^{\mathrm{TM}}$, Phos-Chek $\mathrm{D}-75 \mathrm{~F}^{\mathrm{TM}}$, Fire-Trol LCG- $\mathrm{R}^{\mathrm{TM}}$, and Phos-Chek WD881 ${ }^{\mathrm{TM}}$, whereas the indirect photodegradation is about $50 \%$ in 3.5 and $6 \mathrm{~h}$ and the aerobic degradation with adapted activated sludge is $60 \%$ after 28 days and $74 \%$ after 5 days for diethylene glycol monobutyl ether and ethyl alcohol in Silv-Ex ${ }^{\mathrm{TM}}$, respectively (USDA Forest Service http://www.fs.fed.us/rm/fire/wfcs/msds.htm, accessed 10 May 2008). Chemicals were selected by the US Department of Interior's National Interagency Fire Center, Boise, ID based on use patterns.

We used the limit testing procedure, derived from the traditional acute oral toxicity test methodology (Eaton and Gilbert, 2008) to determine if the $24 \mathrm{~h}$ median lethal dose (LD50) was greater than or less than the predetermined exposure level of $2000 \mathrm{mg}$ chemical/kg body mass. Control and treatment groups consisted of 10 animals (five males and five females). All birds had ad libitum access to feed and water except on the evening prior to dosing, when feed was removed from bobwhites and kestrels. All birds were individually marked with leg bands and conditioned to their cages for at least 2 weeks before initiation of the tests. Compounds were administered orally at a rate of $5 \mathrm{mg}$ chemical/g body mass via gelatin capsule. Size 4 capsules were used for dosing bobwhites and kestrels and size 5 capsules were used for blackbirds. Food coloring (blue, green, and red) was added to capsules given to birds in the control groups in order to detect regurgitation following dosing. All birds were returned to their cages or flight pens post-dosage. Animals were carefully observed for signs of toxicity for $24 \mathrm{~h}$ postdosage and then all survivors were euthanized. Procedures for administering test compounds followed the protocol by Hill and Camardese (1984).

Commercially purchased 16 week old bobwhites were held indoors in brooders with a photoperiod of $16 \mathrm{~h}$ light: $8 \mathrm{~h}$ dark. Bobwhites were fed Purina ${ }^{\mathrm{TM}}$ Gamebird Maintenance Crumble. Captive-bred 9 month old kestrels were housed indoors in individual cages $(33.0(\mathrm{~h}) \times 22.9(\mathrm{w}) \times 38.1(\mathrm{l}) \mathrm{cm})$. Cages were equipped with a $1.27 \mathrm{~cm}$ diameter wooden dowel perch. Tap water was provided by a constricted orifice delivery tube and the diet comprised of Nebraska Brand ${ }^{\mathrm{TM}}$ Bird of Prey Diet and 1 day old domestic chickens. Regurgitated koilin (protective secretion from the gizzard) from the kestrels was collected and fixed in formalin and its histopathological analysis was performed by the Patuxent Wildlife Research Center's veterinarian and a pathologist from the Animal Health Laboratory, Maryland Department of Agriculture, College Park, MD, USA.

Blackbirds were trapped from the wild in Maryland. Birds were held in outdoor flight pens $(2.1(\mathrm{~h}) \times 1.3(\mathrm{w}) \times 6.0(\mathrm{l}) \mathrm{m})$ to accustom them to captivity and fed a blend of Zeigler ${ }^{\mathrm{TM}}$ Soft-billed Bird Diet, cracked corn, and meal worms. Each pen was bisected by a canal $(0.93(w) \times 0.44($ depth $) \mathrm{m})$. Spring water flowed continuously through the canal and was used by the birds for drinking and bathing.

\section{Results}

No bobwhites mortalities occurred during the testing; therefore $24 \mathrm{~h}$ LD50s for the five chemicals were determined to be $>2000 \mathrm{mg}$ chemical $/ \mathrm{kg}$ body mass limit criteria for acute toxicity
(Table 1). Bobwhites exhibited no overt signs of toxicity after $24 \mathrm{~h}$ post-dosage.

There were no kestrel mortalities during the testing but many of the kestrels regurgitated the dose and the partially dissolved capsules. All ten birds regurgitated Fire-Trol LCG- $\mathrm{R}^{\mathrm{TM}}$ and nine of ten birds regurgitated Phos-Chek D-75F ${ }^{\mathrm{TM}}$. Five of ten Fire-Trol GTS- $\mathrm{R}^{\mathrm{TM}}$ treated birds regurgitated the dose whereas three of ten birds regurgitated Phos-Chek WD881 ${ }^{\mathrm{TM}}$. One of ten birds dosed with Silv-Ex ${ }^{\mathrm{TM}}$ regurgitated the capsule. None of the control birds rejected the capsule. Regurgitation occurred within 60 min postdosage. Birds exposed to Silv-Ex ${ }^{\mathrm{TM}}$ exhibited signs of toxicity, including listlessness, tremors, closed eyes, and lack of balance while perching. Birds exposed to the other four chemicals displayed similar signs of toxicity if they did not regurgitate within a few minutes post-dosage. Signs of toxicity were more severe in birds that retained the capsule longer or in birds that did not regurgitate. One kestrel dosed with Silv-Ex ${ }^{\mathrm{TM}}$ escaped while being returned to its cage after dosing and flew around the room several times before collapsing. When returned to its cage, the bird lay prostrate on the cage floor for approximately $5 \mathrm{~h}$ postdosage before exhibiting signs of recovery. One of the birds dosed with Fire-Trol GTS- $\mathrm{R}^{\mathrm{TM}}$ and two of the birds exposed to Phos-Chek $\mathrm{D}-75 \mathrm{~F}^{\mathrm{TM}}$ regurgitated the koilin in addition to the dose. The $24 \mathrm{~h}$ LD50s for Phos-Chek WD881 ${ }^{\mathrm{TM}}$ and Silv-Ex ${ }^{\mathrm{TM}}$ were determined to be $>2000 \mathrm{mg}$ chemical $/ \mathrm{kg}$ body mass regulatory limit criteria for acute toxicity; however the LD50s for the other three chemicals were not quantifiable because of the number of birds which regurgitated the dosage (Table 1 ). No overt signs of toxicity were observed after $24 \mathrm{~h}$ post-dosage.

One of ten blackbirds exposed to Phos-Chek D-75F ${ }^{\mathrm{TM}}$ and three of ten blackbirds exposed to Fire-Trol GTS- $\mathrm{R}^{\mathrm{TM}}$ died in the outdoor pen test, whereas there were no treatment related mortalities in the remaining three chemical groups. None of the birds in the control groups died. The $24 \mathrm{~h}$ LD50s of all five chemicals for blackbirds were determined to be $>2000 \mathrm{mg}$ chemical $/ \mathrm{kg}$ body mass regulatory limit criteria for acute toxicity (Table 1 ). When birds were released into their flight pens following dosing, all birds successfully flew across the canal to the far side of the pen. In general, dosed birds, regardless of test compound, exhibited similar overt signs of toxicity including resting on the bank of the canal, drinking, perching or sitting on the ground on haunches, panting, uncoordination, fluffed feathers, droopy wings, listlessness, and closed eyes. Some affected birds, alert to our presence and movements, flew to perches when disturbed. One Silv-Ex ${ }^{\mathrm{TM}}$ dosed bird on the canal bank leaned forward to drink from the

Table 1

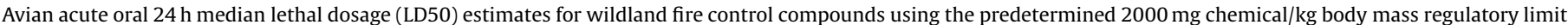
criteria for acute oral toxicity

\begin{tabular}{|c|c|c|c|c|c|c|c|}
\hline \multirow[b]{3}{*}{ Test compounds } & \multicolumn{7}{|l|}{ Species } \\
\hline & \multicolumn{2}{|c|}{$\begin{array}{l}\text { Northern bobwhite (Colinus } \\
\text { virginianus) }\end{array}$} & \multicolumn{3}{|c|}{ American kestrel (Falco sparverius) } & \multicolumn{2}{|c|}{$\begin{array}{l}\text { Red-winged blackbird } \\
\text { (Agelaius phoeniceus) }\end{array}$} \\
\hline & $\%$ mortality ${ }^{\mathrm{a}}$ & LD50 & $\%$ mortality & $\begin{array}{l}\text { \% regurgitated } \\
\text { dose }^{\mathrm{a}}\end{array}$ & LD50 & LD50 & $\%$ mortality \\
\hline \multicolumn{8}{|l|}{ Retardants } \\
\hline Fire-Trol GTS-R ${ }^{\mathrm{TM}}$ & 0 & $>2000$ & 0 & 50 & Not quantifiable ${ }^{b}$ & 30 & $>2000$ \\
\hline Fire-Trol LCG-R ${ }^{\mathrm{TM}}$ & 0 & $>2000$ & 0 & 100 & Not quantifiable & 0 & $>2000$ \\
\hline Phos-Chek D-75F ${ }^{\mathrm{TM}}$ & 0 & $>2000$ & 0 & 90 & Not quantifiable & 10 & $>2000$ \\
\hline \multicolumn{8}{|l|}{ Suppressants } \\
\hline Phos-Chek WD881 ${ }^{\mathrm{TM}}$ & 0 & $>2000$ & 0 & 30 & $>2000$ & 0 & $>2000$ \\
\hline Silv-Ex ${ }^{\mathrm{TM}}$ & 0 & $>2000$ & 0 & 10 & $>2000$ & 0 & $>2000$ \\
\hline
\end{tabular}

\footnotetext{
${ }^{\text {a }} n=10$ birds.
}

${ }^{\mathrm{b}}$ The LD50 could not be estimated because of the number of birds which regurgitated the dosage. 
canal and fell into the water. The bird jumped out and walked to a more advantageous site along the canal (approximately $0.7 \mathrm{~m}$ away) such that it could stabilize itself better during drinking. The survivors displayed no overt signs of toxicity after $24 \mathrm{~h}$ postdosage. None of the above mentioned signs of toxicity were observed in the control groups. Control birds also drank water and flew about the canal post-dosage.

\section{Discussion}

The species tested in these experiments represent three taxonomic groups. Bobwhites were selected as a model species for upland gamebirds and kestrels served as a representative raptor. Blackbirds represented songbirds, the largest avian order in North America. These and other avian species are found in habitats that are subjected to wildland fire control chemicals.

The endpoint of the acute oral toxicity test is lethality and it is expressed by generating a LD50 (the estimated treatment level where $50 \%$ of the test animals have died). The test is a standardized procedure that allows regulatory agencies to use the LD50 as an index for comparing and ranking toxicities of different compounds and sensitivities of different species. The US Environmental Protection Agency classifies pesticides and toxic substances with LD50s $>2000 \mathrm{mg}$ chemical $/ \mathrm{kg}$ body mass as being practically non-toxic (Bascietto, 1985; Smrchek et al., 1993). Since no prior information was available on the toxicities of wildland fire control chemicals to birds and since the ingredients of these products did not appear to be acutely toxic, we used the limit test procedure with the limit dosage of $2000 \mathrm{mg}$ chemical $/ \mathrm{kg}$ body mass for an initial estimation of the acute oral toxicities. Consequently, we minimized the number of animals by using only one exposure level per compound; the traditional acute oral toxicity test methodology involves five or six dosage levels and can use up to 90 animals (Hill, 1992). Our strategy required us to conduct a traditional acute oral toxicity test only if the limit test resulted in $\mathrm{LD} 50<2000 \mathrm{mg}$ chemical $/ \mathrm{kg}$ body mass. Based on the LD50s, wildland fire control chemicals tested in this study show a comparatively low order of acute oral toxicity to the birds.

Regurgitation of the dose was observed in kestrels but not in the other two species. Raptors have evolved an efficient emetic response that allows them to regurgitate the indigestible bones, feathers, scales, and fur of prey items (Balgooyen, 1971). This response may reduce, but not eliminate, exposure to some toxicants (Mineau et al., 1999). Some of the dosed kestrels exhibited signs of toxicity prior to regurgitation and these behavioral effects may reduce a bird's chances of survival in the wild. Three kestrels exposed to the test compounds regurgitated the koilin, the hardened secretion of the tubular glands of the mucosa of the gizzard that protects the underlying tissue layers from damage during the mechanical and chemical digestive processes (Ziswiler and Farner, 1972). Bremner (1979) reported that domestic chicks (Gallus spp.) fed copper diets shed the damaged koilin. We believe that regurgitation of the dosage and the koilin by the kestrels was in response to the irritation caused by these products. We do not believe that the regurgitation was due to the taste of the test compounds because the gelatin capsules containing the dosage were gavaged into the proximal esophagus of the birds, bypassing the buccal taste buds. We also do not attribute the stress of dosing as a significant cause for regurgitation because the kestrels were raised in captivity, all birds in the control group, 7 of the 10 Phos-Chek WD881 ${ }^{\mathrm{TM}}$ treated, and 9 of the 10 Silv-Ex treated kestrels retained their dosage, and regurgitation was not observed with the quail and blackbirds. The koilin and the mucous membrane in some species, including falcons, is loose, allowing sudden and complete shedding of the layers (McAtee, 1917; Ziswiler and Farner, 1972). Gizzards of birds in this stage are empty, suggesting interruption of feeding and digestion until the koilin is renewed (McAtee, 1917). The chances of survival for birds exposed to wildland fire control chemicals in the field will depend on the degree of damage to the gizzard lining and its consequent ability to secrete the koilin.

Physiological and environmental stressors can increase the sensitivity of birds to chemicals. Grue (1982) concluded that high temperatures and physiological stress of the post-nuptial molt were responsible for the greater sensitivities of common grackles (Quiscalus quiscula) to pesticides in late summer than in the spring. Rattner et al. (1987) demonstrated up to a two-fold increase in pesticide toxicity to Japanese quail (Coturnix japonica) chronically exposed to heat or cold, when compared with quail housed at thermoneutral temperature. In our study, the potential interaction between physiological stress and wildland fire control chemicals may have been demonstrated by the kestrel which escaped from its cage immediately after being dosed with Silv$\mathrm{Ex}^{\mathrm{TM}}$. The bird flew several circles in the room (approximately $3.9 \times 3.6 \mathrm{~m}$ ) without colliding with the walls and cages before collapsing. Subsequent periodic observations revealed this bird to exhibit the severest signs of toxicity and for the longest duration post-dosing of all kestrels. An environmental stressor (e.g. low temperature) could have influenced the survival of the blackbirds exposed to Fire-Trol GTS-R ${ }^{\mathrm{TM}}$. The night-time low temperature during the Fire-Trol GTS- $\mathrm{R}^{\mathrm{TM}}$ test was $-4.4^{\circ} \mathrm{C}$, the lowest temperature during the five outdoor blackbird tests. Therefore, the three mortalities observed in this test may be due to the interaction of the Fire-Trol GTS-R ${ }^{\mathrm{TM}}$ and the cold. Our limited observations suggest that stressors can enhance the toxicity of wildland fire control chemicals to birds.

\section{Conclusion}

The acute oral toxicity test is conventionally used by regulatory agencies for the preliminary evaluation of potential toxins. However the test is not designed to evaluate sublethal, chronic, and indirect effects, routes of exposure, actual field concentrations, and application methods; nor does it account for the diverse ecology and behavior of avian species that can modulate their exposure to the chemicals and affect survival. The toxicity of a particular chemical may vary by more than an order of magnitude among closely related species (Hill, 1992). Furthermore, due to the inherent differences between the laboratory and the field, chemical concentrations in the environment need not be as high as the treatment levels used in laboratory tests to result in adverse effects to birds in the field (Vyas et al., 2006). Whereas our results characterize the hazards of these wildland fire control products, much of the information required by regulatory agencies for conducting risk assessments is not available. Research and monitoring are needed to determine the residue concentrations on avian food items, characterize environmental fate, and document adverse toxic effects to birds in the field following operational applications. The five wildland fire control chemicals are categorized as practically non-toxic to birds on an acute oral basis, but the above limitations of the testing methodology and the interactive effects of environmental stressors may manifest adverse effects in the field that cannot always be predicted from the laboratory tests.

\section{Acknowledgements}

This research was funded by cooperative agreement with the US Fish and Wildlife Service and the National Interagency Fire 
Center, Boise, Idaho, USA. We thank George and Johnson of the US Forest Service for providing the test chemicals; Schlobohm and Bass of US Bureau of Land Management for valuable information about the test chemicals; Evans and Smrchek of the US Environmental Protection Agency for technical assistance on chemical regulations; Klein and Green for veterinarian expertise in identifying the koilin; Klimkiewicz and LeCompte Wildlife Management Area, Maryland Department of Natural Resources for assistance with trapping red-winged blackbirds; Bauer, DeCrappeo, Federoff, Garland, Jakob, Jaquette, Knipling, Niebur, and Olsen for animal care and experimental assistance; Heinz and Rattner for technical assistance; and Albers, Beyer, Hoffman, Pattee and the three anonymous reviewers for reviewing the manuscript.

\section{References}

Balgooyen, T.G., 1971. Pellet regurgitation by captive sparrow hawks (Falco sparverius). Condor 22, 382-385.

Bascietto, J., 1985. Avian single dose oral LD50. Standard Evaluation Procedure. US Environmental Protection Agency EPA-540/9-85-007. (Washington, DC, USA).

Bremner, I., 1979. Copper toxicity studies using domestic and laboratory animals. In: Nriagu, J.O. (Ed.), Copper in the Environment. Part 2: Health Effects. Wiley, New York, pp. 285-306.

Eaton, D.L., Gilbert, S.G., 2008. Principles of toxicology. In: Klaassen, C.D. (Ed.) Casarett and Doull's Toxicology. The Basic Science of Poisons, seventh ed. McGraw-Hill, New York, pp. 11-44.

George, C.W., Blakely, A.D., Johnson, G.M., 1976. Forest fire retardant research. A status report. USDA Forest Service Research Paper, Intermountain Forest and Range Experimental Station, General Technical Report INT-31, Ogden.
Grue, C.E., 1982. Response of common grackles to dietary concentrations of four organophosphorus pesticides. Arch. Environ. Contam. Toxicol. 11, 617-626.

Hill, E.F., 1992. Avian toxicology of anticholinesterases. In: Ballantyne, B., Marrs, T.C. (Eds.), Clinical and Experimental Toxicology of Organophosphates and Carbamates. Butterworth-Heinemann, Boston, pp. 272-294.

Hill, E.F., Camardese, M.B., 1984. Toxicity of anticholinesterase insecticides to birds: technical grade verses granular formulations. Ecotoxicol. Environ. Saf. 8, 551-563.

McAtee, W.L., 1917. The shedding of the stomach lining by birds, particularly as exemplified by the Anatidae. Auk 34, 415-421.

McKenzie, D., 1992. Foam vs. Fire Primer. USDA Forest Service, San Dimas Technology and Development Center 9251 1209, NWCG-446-2, PMS 446-2, or NFES 2270. (San Dimas, CA, USA) Available at <http://www.fs.fed.us/eng/pubs/ pdf/92511209.pdf $>$ [Verified 19 December 2007].

Mineau, P., Fletcher, M.R., Glaser, L.C., Thomas, N.J., Brassard, C., Wilson, L.K., Elliott J.E., Lyon, L.A., Henny, C.J., Bollinger, T., Porter, S.L., 1999. Poisoning of raptors with organophosphorus and carbamate pesticides with emphasis on Canada, US and UK. J. Raptor. Res. 33, 1-37.

Rattner, B.A., Becker, J.M., Nakatsugawa, T., 1987. Enhancement of parathion toxicity to quail by heat and cold exposure. Pestic. Biochem. Physiol. 27, 330-339.

Smrchek, J.R., Clements, R., Morcock, R., Rabert, W., 1993. Assessing ecologic al hazard under TSCA: methods and evaluation of data. In: Landis, W.G., Hughes, J.S., Lewis, M.A. (Eds.), Environmental Toxicology and Risk Assessment. American Society for Testing and Materials Special Technical Publication 1179, American Society for Testing and Materials, Philadelphia, pp. 22-39.

Vyas, N.B., Spann, J.W., Hulse, C.S., Borges, S.L., Bennett, R.S., Torrez, M., Williams, B.I., Leffel, R., 2006. Field evaluation of an avian risk assessment model. Eviron. Toxicol. Chem. 25, 1762-1771.

Ziswiler, V., Farner, D.S., 1972. Digestion and the digestive system. In: Farner, D.S., King, J.R., Parkes, K.C. (Eds.), Avian Biology, Vol. 2. Academic Press, New York City, pp. 343-410. 